\title{
The Evaluation of the Patients with Clefts in Aegean Region in Turkey between the Years 2000 to 2011
}

\author{
Ege Dogan1, Erdal Isıksal'2, Servet Dogan'1 \\ ${ }^{1}$ Department of Orthodontics, School of Dentistry, Ege University, Izmir, Turkey \\ ${ }^{2}$ Private Practice, Izmir, Turkey \\ Email: servetdgn@hotmail.com
}

Received 16 April 2014; revised 30 May 2014; accepted 14 June 2014

Copyright @ 2014 by authors and Scientific Research Publishing Inc.

This work is licensed under the Creative Commons Attribution International License (CC BY). http://creativecommons.org/licenses/by/4.0/

(c) (i) Open Access

\begin{abstract}
Purpose: The evaluation of the patients with clefts; the number, type, distribution by gender, etiological factors in Aegean region in Turkey between the years 2000 to 2011. Material and Method: The patients with clefts who referred to Ege University from different cities were evaluated. The number of the clefts, the type of the clefts, and the causative etiological factors which were known, were recorded for each year separately, from 2000 to 2011. At the same time, the distribution of the gender was made for each year. Chi-square test is used for the statistical evaluation. Results: According to the results of the study, the numbers of the patients with clefts were increased day by day. Totally 741 (49.6\% female, $50.4 \%$ male) patients with clefts were identified. Unilateral complete cleft lip and palate appeared in the left side was seen more in males (23.8\%), while seconder palate cleft was seen more in females (16.7\%). Drugs, which were used in the first trimester of the pregnancy, were the most seen etiological factors for the clefts $(42.5 \%)$, while genetic was $23.3 \%$ only. Conclusion: The prevention for one of the mostly seen congenital anomaly; cleft lip and palate is still unknown. For this reason, the determination of the newborn babies with cleft lip and palate has an important role in order to give these patients more effective treatment.
\end{abstract}

\section{Keywords}

Patients with Clefts, Aegean Region

\section{Introduction}

Cleft lip and palate, a congenital anomaly is one of the most seen anomalies. It is a serious problem both for the patient and the family. Prenatal ultrasound will often detect cleft lip but cleft palate is not always detected. The 
people who have cleft lip and palate need a multidisciplinary treatment. Parents should contact to specialists experienced in diagnosis, management and treatment of children with cleft lip and palate [1]-[6].

The studies done with genetics show us new results about the reasons of having a cleft lip and palate. When the literatures are searched, we can see more studies about prevention of clefts than the treatment of clefts [4] [6]-[9].

Clinical genetic evaluation is the main component in the management of patients with congenital craniofacial anomalies. The evaluation should include diagnosis, recurrence risk counseling, and counseling regarding prognosis. Complete genetic evaluation include: family history, prenatal and postnatal growth deficiency, developmental delay or mental retardation, associated major and minor malformations and disorders inconsistent with the genetic background [10]-[15].

It is important for the society to know the number of the patients with cleft lip and palate, the etiological factors, the type of the cleft and the gender of the patient [1] [4] [5] [11] [15].

The aim of this study is to evaluate the patients with clefts; the number, type, distribution by gender, etiologic factors in Aegean region of Turkey between the years 2000 to 2011.

\section{Material and Method}

The study is done by the evaluation of the patients with cleft lip and palate in Izmir and around Izmir (the Aegean Region of Turkey) who had visited the Ege University, Dentistry Faculty, Department of Orthodontics to be treated, between the years 2000-2011.

The archieves, patient cards and models were evaluated in order to classify the number, the type, the location of the cleft, the distribution by gender and the etiological factors of the cleft lip and palate. Kernahan-Stark classification, which is still commonly in use, is used to evaluate the cleft type, between the years 2000-2011. These factors were evaluated; the distribution by gender, the rate of the unilateral clefts; right or left sided, the factors affecting the etiology of the clefts; genetics, relative marriage, the drugs which the mother used during the first trimester of her pregnancy and the other factors during the first trimester of the pregnancy. Chi-square is used to evaluate the distribution between males and females, and the etiological factors.

\section{Results}

In this study, we found out that 741 patients visited the clinic, but only 592 of them had the information about the etiological factors. All 741 had the information of type of the cleft and gender of the patient.

In Table 1, the number of patients, the distribution by gender and the most seen anomaly are shown. In Table 2, the etiological factors collected by the archive data are shown.

\section{Discussion}

Orofacial clefts like cleft lip and palate are among the most common birth defects in all populations around the world. The etiology is still unknown for the clefts but the genetic factors, some environmental factors and some syndromes have a direct relation with clefts. An abnormality in the first trimester in the intrauterine life affects the normal growth and development of the fetus and this causes irreversible defects [1] [2] [8] [9] [15] [16].

Table 1. Distribution of the patients with cleft by gender and type of the anomaly.

\begin{tabular}{|c|c|c|c|c|}
\hline \multirow{3}{*}{ Total Number } & \multirow{3}{*}{ Females } & \multirow{3}{*}{ Males } & \multicolumn{2}{|c|}{ THE MOST SEEN ANOMALY } \\
\hline & & & \multicolumn{2}{|c|}{ Distribution } \\
\hline & & & Females & Males \\
\hline \multirow{4}{*}{741} & \multirow{3}{*}{368} & \multirow{3}{*}{373} & $\begin{array}{l}\text { Complete Seconder } \\
\text { Palate Cleft }\end{array}$ & Left Sided \\
\hline & & & & $\begin{array}{l}\text { Primer Seconder } \\
\text { Palate Cleft }\end{array}$ \\
\hline & & & 124 & 177 \\
\hline & $49.6 \%$ & $50.4 \%$ & $16.7 \%$ & $23.8 \%$ \\
\hline
\end{tabular}


Table 2. Distribution of the etiological factors of the patients with cleft.

\begin{tabular}{ccc}
\hline \multicolumn{3}{c}{ Total number of the patients evaluated for etiological factors $=592$} \\
\hline ETIOLOGICAL FACTORS & Number & $\%$ \\
\hline Genetics & 138 & 23.3 \\
Consanguineous Marriage & 156 & 26.3 \\
Drugs used in first trimester & 252 & 42.5 \\
Other etiological factors & 46 & 7.7 \\
\hline
\end{tabular}

Craniofacial anomalies may not fully express clinical manifestations that can be recognized in the first year of life like isolated seconder palatal cleft. Cleft lip and palate has many varieties so it is easier to group the deformations to define the cleft type clearly. So many researchers had developed their own classification method [1] [2] [6] [7] [10] [12]-[14].

Clefts of both the lip and palate may be unilateral or bilateral. It may be complete or incomplete. A remarkable range of variation exists in each category so various degrees of incompleteness of the cleft in the lip and palate may exist in combinations. Kernahan and Stark's classification is commonly used, because it determines the type of the defects more clearly and easy for the doctor [12] [13].

There are many studies done about the incidence of the cleft lip and palate. According to these studies ethnical and racial variations are very wide. It is reported that the population of Asia has the highest incidence (0.79 3.74 per 1000 Asians), the population of the white race has an incidence in the middle (0.91 - 2.69) and the population of Africa has the lowest incidence (0.18 - 1.67). It is reported that only a lip cleft or only a palate cleft incidence is lower than the lip plus palate cleft incidence The $33 \%$ of these deformities is unilateral lip with/without palate cleft [7]-[9] [11]-[16].

Studies done show the result that the number of males with cleft lip and palate is two times higher than the females. Localized palate clefts are more seen in females and $70 \%$ of the unilateral clefts are left sided. Left sided clefts are mostly seen in males and right sided clefts are mostly seen in females. It is also reported that the unilateral clefts are more seen than bilateral clefts. The lip cleft with/without palate cleft or just a lip cleft is more seen in males than females but on the other hand, isolated palate cleft is more seen in females than males [7] [10] [14] [16]. These results overlap with our study.

Complete genetic evaluation include; family history, prenatal and postnatal growth deficiency, developmental delay or mental retardation, associated major and minor malformations and disorders inconsistent with the genetic background. The mutations happen in the genes, which are responsible for the development of lip and palate, are caused if the mother smokes or drinks alcohol, doesn't get enough folic acid during the first trimester of the pregnancy, gets radiation, gets some diseases which cause fever, uses steroids, anticoagulants and the environmental factors. This mutation causes some congenital anomalies like cleft lip and palate. It is reported that $70 \%$ of the babies with cleft lip and palate have a congenital syndrome and 30\% don't have a congenital syndrome. There are many genes which cause cleft lip and palate without any congenital syndromes [8] [9] [11] [15] [16].

Concerning the etiology of cleft lip and palate, there is general agreement upon the multifactorial heredity, which is partly due to genetic and partly due to environmental factors. The etiology and the incidence of the cleft lip and palate have a relation with the ethnical structure of the population which is examined. In our study; the most seen etiological factor except the consanguineous marriage is drugs, which the mother uses during the first trimester of her pregnancy. These drugs are: anticonvulsives, cortisone preparations and the drugs used for abortion but more detailed study is need for the exact information [8] [9] [11] [15].

A mother who had her first baby with cleft has a 3.7\% risk for having her second baby with cleft lip and palate but 2.5\% risk for having the second baby only with palate cleft. If one of the parents has a cleft lip and palate, the risk for second baby to have cleft lip and palate is $4 \%$, if their first baby is born without any cleft lip and palate. If the parents don't have a cleft lip and palate, but their first baby has cleft lip and palate with other anomalies, the risk for second baby to have a cleft lip and palate is $2 \%$. If parents had a baby with a palate cleft before, there is no risk for second baby to have a cleft lip and palate. If the baby doesn't have a relative with cleft lip and palate, this baby has $2 \%$ risk for having a palate cleft but if the baby has a relative with a cleft, this baby has a 7\% risk to have a palate cleft. If a mother or father has a palate cleft, the baby doesn't have a risk for having a cleft lip and palate together, but there is a $6 \%$ risk for first baby, $15 \%$ risk for second baby to have just a palate cleft [9] [11] [14] [15]. 
Dogan [3], found out that 585 babies had visited Ege University Department of Orthodontics between November 1976 to May 1979. Unilateral complete and left sided clefts were mostly seen. The average number of the patients per year is 45 .

In our study, its noticeable that the numbers got higher in the recent years even there was lack in the archieve records. If this study is done all over the Turkey, in all the university clinics and in the hospitals, newborn babies with cleft lip and palate who needs a multidisciplinary treatment protocol can be determined specifically. This will help the patients and their family more effectively during the treatment process.

\section{Conclusions}

Oral clefts are the most common facial malformation. With improvements in the resolution of ultrasound equipment and technique, craniofacial malformations of the fetus can be determined. Prenatal ultrasound will often detect cleft lip but cleft palate is not always detected.

The number of cleft lip and palate patients between the years 2000-2011 reported in Orthodontics Department of Ege University is 741 babies (49.6\% female, $50.4 \%$ male). In male babies, left sided complete primer seconder cleft is seen more. In female babies, the seconder cleft is seen more. Mother using drugs during the first trimester of her pregnancy is the most seen etiological factors.

The prevention of cleft lip and palate is still unknown. The determination of the newborn babies with cleft lip and palate has an important role in order to give these patients more effective treatment.

\section{References}

[1] Aduss, H. (1971) Craniofacial Growth in Complete Unilateral Cleft Lip and Palate. Angle Orthodontics, 4, $202-213$.

[2] Doğan, S., Önçağ, G. and Akın, Y. (2006) Craniofacial Development in Children with Unilateral Cleft Lip and Palate. British Journal of Oral and Maxillofacial Surgery, 44, 28-33.

[3] Doğan, S., Ölmez, S., Aydınlı, E. and Bilkay, U. (2011) Treatment Modalities of a Unilateral Cleft Lip and Palate Patient from Birth to Adulthood-Case Report. Ortho Techniques, 3 (Digital issue).

[4] Jones, M.C. (1988) Etiology of Facial Clefts. Prospective Evaluation of 428 Patients. Cleft Palate Journal, 25, 16-20.

[5] Thompson, J.S. and Thompson, M.W. (1980) Genetics in Medicine. 3rd Edition, W.B. Saunders, Philadelphia, 111.

[6] Bardach, J. and Morris, H.L. (1990) Multidisciplinary Management of Cleft Lip and Palate. W.B. Saunders, Philadelphia, 121.

[7] Gorlin, R.J., Cohen, M.M. and Hennekam, R.C.M. (2001) Syndromes of the Head and Neck. 4th Edition, Oxford University Press, Delhi, 850-860.

[8] Hanson, J.W. and Murray, J.C. (1990) Genetic Aspects of Cleft Lip and Palate. In: Multidisciplinary Management of Cleft Lip and Palate, W.B. Saunders, Philadelpha, 121.

[9] Vanderas, A.P. (1987) Incidence of Cleft Lip, Cleft Palate and Cleft Lip and Palate among Races: A Review. Cleft Palate Journal, 24, 216.

[10] Elsahy, N.I. (1973) The Modified Striped Y - A Systematic Classification for Cleft Lip and Palate. Cleft Palate Journal, 10, 247-250.

[11] Friedman, H.I., Sayetta, R.B., Coston, G.N. and Hussey, J.R. (1991) Symbolic Representation of Cleft Lip and Palate. The Cleft Palate-Craniofacial Journal, 28, 252-259. http://dx.doi.org/10.1597/1545-1569(1991)028<0252:SROCLA >2.3.CO;2

[12] Harkins, C.S., Berlin, A., Harding, R.L., Longacre, J.J. and Snodgrasse, R.M. (1962) A Classification of Cleft Lip and Cleft Palate. Plastic \& Reconstructive Surgery, 29, 31-39. http://dx.doi.org/10.1097/00006534-196201000-00005

[13] Kernahan, D.A. and Stark, R.B. (1958) A New Classification for Cleft Lip and Palate. Plastic \& Reconstructive Surgery, 22, 435-441. http://dx.doi.org/10.1097/00006534-195811000-00001

[14] Kernahan, D.A. (1971) The Striped Y-A Symbolic Classification for Cleft Lips and Palates. Plastic \& Reconstructive Surgery, 47, 469-470. http://dx.doi.org/10.1097/00006534-197105000-00010

[15] Schwartz, S., Kapala, J.T., Rajchgot, H. and Gordon, L.R. (1993) Accurate and Systematic Numerical Recording System for the Identification of Various Types of Lip and Maxillary Clefts (RPL System). The Cleft Palate-Craniofacial Journal, 30, 330-332. http://dx.doi.org/10.1597/1545-1569(1993)030<0330:AASNRS >2.3.CO;2

[16] Doğan, S. (1989) The Evaluation of the Cleft Lip and Palate Patients from November 1976 to May 1989 in Izmir and around İzmir. İzmir Diş Hekimleri Odası Dergisi, 3, 12-15. 
Scientific Research Publishing (SCIRP) is one of the largest Open Access journal publishers. It is currently publishing more than 200 open access, online, peer-reviewed journals covering a wide range of academic disciplines. SCIRP serves the worldwide academic communities and contributes to the progress and application of science with its publication.

Other selected journals from SCIRP are listed as below. Submit your manuscript to us via either submit@scirp.org or Online Submission Portal.
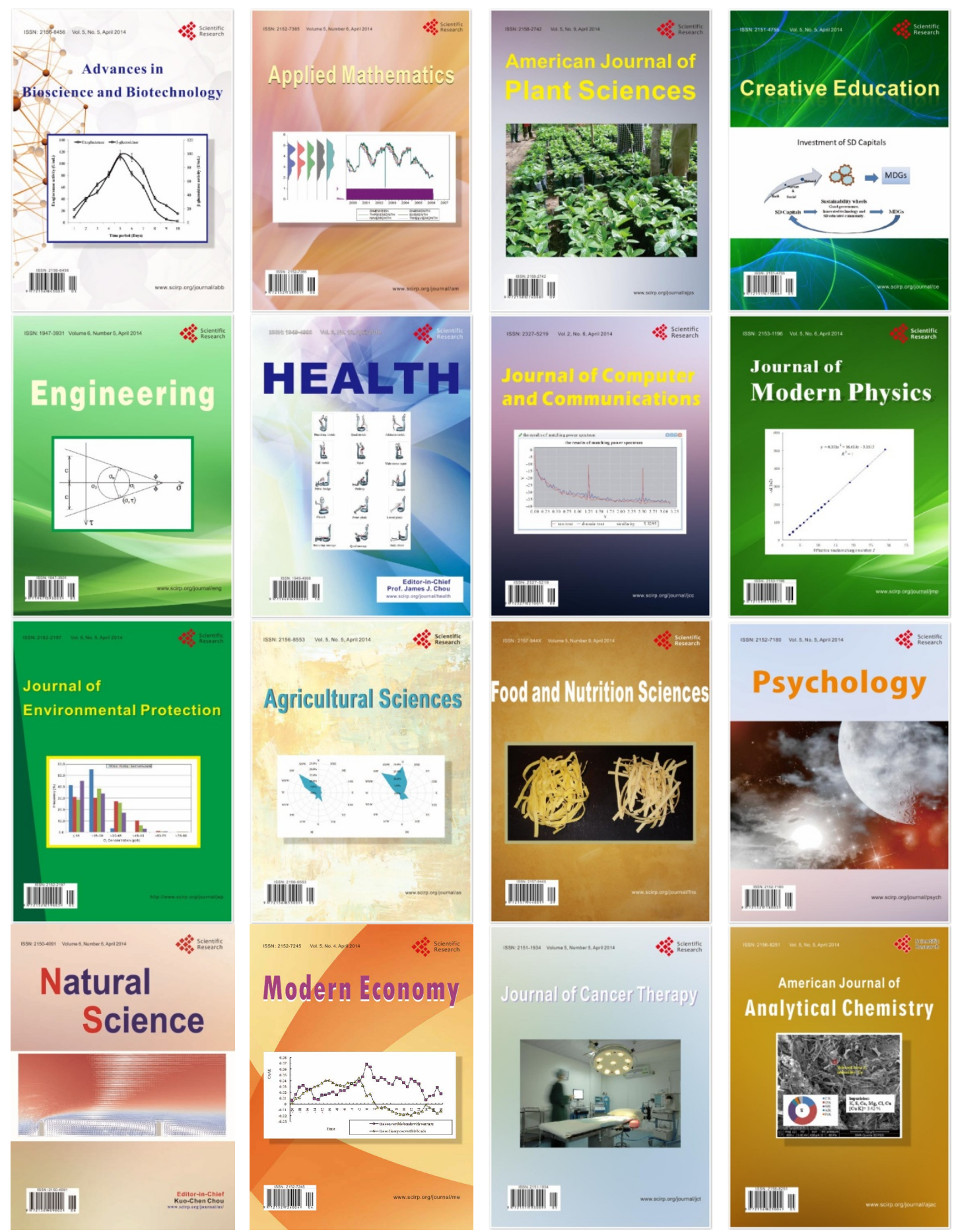